ARBOR CIENCIA PENSAMIENTO Y CULTURA CLXXXI 714 JULIO-AGOSTO (2005) 181-197 ISSN: 0210-1963

\title{
PÍO DEL RÍO HORTEGA EN LA UNIVERSIDAD DE VALLADOLID
}

\author{
Juan Riera Palmero \\ Catedrático de Historia de la Ciencia de la Unversidad de Valladolid
}

\begin{abstract}
The article describes the creation of the first Histology Chair at the Valladolid University, their consecutives professors ( Aureliano Maestre de San Juan and Leopoldo López Garcia ), the institutionalization of the Histology and Pathological Anatomy Chairs and the first academic period of Isaac Costero and Rio Hortega. A facsimile of the Master Degree exercises of Rio Hortega is included.
\end{abstract}

KEY WORDS Valladolid University. Histology and Pathological Anatomy Chairs. End of XIX at first of XX centuries. Aureliano Maestre de San Juan. Leopoldo López García. Isaac Costero. Pio del Río Hortega. Santiago Ramón y Cajal..
RESUMEN El artículo describe la creación en 1873 de la primera Cátedra de Histología en la Universidad de Valladolid y sus sucesivos profesores: Aureliano Maestre de San Juan y Leopoldo López García, la institucionalización de la Histología y la Anatomía Patológica como disciplinas, y los inicios académicos de Isaac Costero y Pío del Río Hortega. Se incluyen, en facsímil, los ejercicios de Licenciatura de Río Hortega..

PALABRAS CLAVE Universidad de Valladolid. Finales del siglo XIX y principios del XX. Histología y Anatomía Patológica. Aureliano Maestre de San Juan. Leopoldo López García. Isaac Costero. Pio del Rio Hortega. Santiago Ramón y Cajal.
La figura histórica de don Pío del Río Hortega y su proyección científica constituye un capítulo destacado de la briIlante escuela española de Histología. Para situar su obra debe tenerse en cuenta, como señaló el propio Río Hortega en una ocasión: "Tuve cuatros auténticos maestros -refería en 1942-. El primero, mi padre, que me enseñó a conducirme rectamente; otro, don Leopoldo López García, que me adiestró en los principios de la Histología. El tercero, Nicolás Achúcarro, que fue mi iniciador en las investigaciones neurológicas. Y el cuarto, Santiago Ramón y Cajal, quien me enseñó a ser perseverante y a no renunciar al idealı.

En España el reconocimiento universitario de la histología tuvo lugar en 1873, fecha de creación de la primera cátedra de la disciplina en la Facultad de Medicina de Madrid. El primer titular de la asignatura fue Aureliano Maestre de San Juan, quien pese a la modesta labor escrita, debe considerarse como el iniciador de los estudios histológicos, especialmente a través de su magisterio en la figura de Santiago Ramón y Cajal. Es interesante recordar que Maestre de San Juan fue maestro de Leopoldo López Garcia, futuro catedrático de Valladolid, en cuya Universidad se inició años más tarde la segunda gran figura junto a Cajal, nos referimos a Pío del Río Hortega. A Maestre de San Juan debemos en buena medida la institucionalidad de la disciplina, puesto que cultivó con decoro la especialidad, dándole un enorme impulso con la creación de la Sociedad Española de Histología en 1874. Maestre, que se había formado como Silóniz, en Paris, al regresar a Madrid formó la primera generación de histólogos españoles, a la que por méritos propios pertenecen, entre otros, Santiago Ramón y Cajal, y López García. Este último, tras un viaje de estudios a Paris, quedó vinculado a la Universidad de Valladolid en 1888, años decisivos en los que Ramón y Cajal estaba en plena elaboración de la teoria de la neurona, llegando más tarde a la obtención del Premio Nobel.

Las nuevas enseñanzas se iniciaron en nuestra Universidad con Leopoldo López García en el curso 1888-89, año en que fue creada esta Cátedra universitaria y se llevó a cabo una profunda transformación del Hospital de la Facultad de Medicina. Aunque López Garcia, nacido en Madrid, se habia doctorado en la Universidad central, su largo vida académica quedó definitivamente unida al claustro vallisoletano hasta su jubilación, acaecida en 1924.

La institucionalización de la Histología y Anatomía Patológica en Valladolid con unos comienzos modestos tuvo un decisivo impulso con Leopoldo López García. Este profesor junto a Río Hortega e Isaac Costero, fueron las figuras más importantes que Valladolid tuvo en el área histopatológica, figuras relacionadas como veremos seguidamente. Los tres 
científicos mantuvieron estrecha relación con la Universidad de Valladolid. Costero coincidió con Río Hortega en España y en el exilio americano tras la contienda civil, incluso ambos publicaron trabajos en estrecha colaboración. Por otra parte, Costero en su primera etapa vallisoletana coincidió hasta 1932, año en que muere López García, con éste en la ciudad de Valladolid. El paulatino pero eficaz esfuerzo a favor de la disciplina, desde 1888-1889, hasta 1936, se vio truncado por razones político-sociales que abrieron una fractura en un panorama esperanzador para la Histología y Anatomía Patológica vallisoletana.

Las relaciones científicas y académicas debieron existir entre los morfólogos e histopatólogos. Sabemos, que Salvino Sierra y Val, Catedrático de Anatomía Humana, fue docente de Histología sólo provisionalmente. Asimismo es necesario subrayar que las afinidades metodológicas y coincidencias entre morfología descriptiva e histopatología se hicieron de nuevo patentes en los primeros lustros del siglo XX. Confirma nuestro anterior aserto el hecho que Río Hortega fuera alumno interno de la Cátedra de Anatomía, bajo el magisterio primero de Salvino Sierra y posteriormente de Leonardo de la Peña, figuras que se cruzaron en la formación de nuestro histopatólogo, al menos en sus primeros balbuceos vacacionales, a los que Río Hortega aludirá más tarde en su obra. Los primeros trabajos científicos de Rio Hortega, las historias clínicas, asi como los materiales de autopsia que figuran en su tesis del doctorado, pertenecen en parte a las pesquisas realizadas en el anfiteatro anatómico de la Facultad de Medicina de Valladolid. La peripecia vocacional de nuestro científico, pasó por Anatomía, se interesó por la clinica, muy fugazmente, para decantarse definitivamente por la investigación micrográfica. La convivencia de Río Hortega con otro gran anatomista vallisoletano, Ramón López Prieto, amigo y condiscipulo, con quien mantuvo una entrañable relación que todavía recordará López Prieto y el propio Río Hortega a lo largo de su existencia histórica. La inicial ayuda de Ramón López Prieto a nuestro biografiado debió ser decisiva a juzgar por las palabras del primero cuando lo recordaba en una fecha tan lejana como la del homenaje de 1931: «Poco tiempo después -refiere textualmente López Prieto- coincidiendo con el comienzo de mi labor en la cátedra, fue cuando Del Río comenzó a sentir en serio el deseo de dedicarse de lleno a la investigación, y se refugió, como único medio de poder aislarse, en una modernisima habitación que pude facilitarle, al lado del antiguo anfiteatro pequeño de Anatomia, llevando a ella su material particular, microtomo, reactivos, etc., porque alli falta- ban los más indispensables medios de trabajo». Esta visión de los balbuceos iniciales de Río Hortega como histólogo, concuerdan plenamente con las palabras del maestro cuando al acordarse de don Leonardo de la Peña, en su libro El Maestro y yo, nos refiere don Pío, al incorporarse aquel profesor a la Cátedra de Anatomía en 1909: «Regresaba -de la Peña- a Valladolid para regentar la Cátedra de Anatomía y hacer clientela como especialista de vías urinarias. Precisa$\mathrm{ba}$, en este segundo aspecto, una persona a quien confiar los trabajos de laboratorio y pensó que yo podía serle útil. Me animó a ir a su lado -prosigue Río Hortega- ofreciéndome todos los análisis que precisara su clientela con los que podria satisfacer mis escasas ambiciones pecuniarias. Acepté agradecido la distinción que se me hacía y la oportunidad que se me brindaba de vivir en un ambiente más de mi agrado y monté en Valladolid un modesto laboratorio en el que, en espera de los prometidos análisis, comencé los estudios microscópicos. Por fortuna, aquéllos no llegaron, pues mi mecenas no cumplió sus ofrecimientos. Yo, en cambio, asistía diariamente al pequeño laboratorio de la Cátedra de Anatomía donde no escaseaban los análisis gratuitos".

Don Pío del Río Hortega había nacido en Portillo en 1882 procedia de familia acomodada, fue alumno de la licenciatura de Medicina, grado que obtuvo en Valladolid el 16 de junio de 1905. Los estudios y las calificaciones obtenidas muestran a un alumno aventajado, sin embargo los ejercicios realizados para el premio extraordinario de la licenciatura sobre la angina diftérica y la úlcera, son dos modelos de buen gusto literario y un dominio del idioma castellano que denotaban una exquisita sensibilidad. Ambas disertaciones que conserva el Archivo Universitario de Valladolid, son quizá los primeros trabajos que nos han llegado cuando Río Hortega contaba apenas veintitrés años.

Superados los estudios de Medicina, y después de varios intentos pasajeros de ejercer la profesión en Portillo, tras obtener el grado de Doctor en Madrid, nuestro biografiado estuvo vinculado al claustro de Medicina vallisoletana durante un breve trienio, entre 1911 y 1913, a los que seguirá el periodo más decisivo de su vida científica en Madrid. La presencia de Pío del Río Hortega en la Facultad castellana se refleja en un breve expediente administrativo, que es insuficiente para adentrarse en la peripecia personal del maestro en estos años de aprendizaje. Nombrado por Real Orden de 5 de junio de 1911 desempeñaría el cargo hasta el 31 de diciembre de 1913, en que cesó por renuncia para 
pasar a Madrid. Las referencias que se recogen en los Libros de Actas de la Facultad de Medicina son muy someras, limitándose a citarle en dos ocasiones a lo largo de estos años. El paso de Río Hortega por nuestra Facultad fue fugaz pero su huella le acompañó durante toda su existencia histórica; fueron los años de incertidumbre en los que una opción personal y los acaeceres académicos que le rodearon a la sazón, los que, consolidaron la profunda vocación de histólogo que Río Hortega supo adoptar con gran lucidez. El ejemplo se repetiría años más tarde con Costero también docente durante un lustro en la Facultad de Valladolid, pero cuyo recuerdo le acompañó durante su definitivo exilio mexicano hasta su muerte.

Ambos, Costero y Río Hortega, tuvieron estrecha relación a lo largo de su vida científica, ambos fueron profesores en la misma Facultad vallisoletana y en la misma disciplina. Pertenecian a la segunda gran promoción de la Escuela Española de Histología, siendo en numerosos aspectos dos destinos paralelos en el exilio de 1939. La relación personal entre Costero y Río Hortega se inició en Madrid, cuando aquél fue becado por el Laboratorio de Histopatología de la Junta para Ampliación de Estudios e Investigaciones Científicas, que dirigia en Madrid don Pío del Río Hortega. Es evidente que Isaac Costero exige merecidísimo elogio, pues fue sin disputa uno de los más ilustres histólogos españoles del pasado siglo. Trabajó en el Instituto de Oncología de Madrid y en las Universidades alemanas durante los años 1931 y 1932. Entre sus maestros extranjeros figuran el profesor Caspari y la doctora Wollman, quienes le iniciaron en la difícil técnica de cultivo de tejidos, quehacer en el que sobresalió Isaac Costero. Asistió este histopatólogo durante dos meses al Instituto de Patología del Hospital Mohabit de Berlín, que a la sazón dirigía el profesor Benda.

El segundo y decisivo maestro que tuvo Rio Hortega fue Nicolás Achúcarro (1880-1918), cuya obra realmente genial se vio truncada por una muerte acaecida en plena madurez. Achúcarro había sido discípulo de Cajal, aunque su formación neuropsiquiátrica le orientó hacia la investigación de la Anatomía microscópica del sistema nervioso. Achúcarro es otro de los gigantes de la Ciencia Histológica universal del siglo XX. Trabajó en París con Babinski y Pierre Marie, más tarde Achúcarro, en Italia tuvo relación científica con neuropsiquiatras tan famosos como Ernesto Lugaro y Eugenio Tanzi. Su periplo europeo se vio coronado cuando en Munich asistió a las enseñanzas de Emil Kraepelin y Alois Alzheimer. El prestigio científico de Achúcarro le llevó, por recomendación directa de Alzheimer, a dirigir el Departamento Anatomopatológico del Manicomio Federal de Washington durante dos años, aunque por razones familiares regresó a España. Es opinión generalizada que estos tres científicos, Cajal, Achúcarro y Rio Hortega, han escrito algunas de las páginas más brillantes de la Ciencia española del periodo contemporáneo, llevando la investigación histológica del sistema nervioso a un primer plano de interés mundial.

La relación Río Hortega con Achúcarro se produjo en Madrid, a donde habia marchado nuestro científico. Fue en el Laboratorio fundado por la Junta para Ampliación de Estudios donde Achúcarro tuvo como discípulo a Río Hortega y a figuras tan conocidas como Gonzalo Rodríguez Lafora, Felipe Jiménez de Azúa, José Miguel Sacristán, Luis Calande y Miguel Gayarre, entre otros que, por razones de concisión, no citamos. La estrecha relación científica de Achúcarro con Río Hortega se produjo a partir de 1915. Con anterioridad Río Hortega habia sido becado para su formación microscópica y cancerológica en centros de París y Londres. De nuevo en Madrid, trabajó, desde la fecha señalada, en el Laboratorio de la Junta, bajo las enseñanzas de Achúcarro. Cuando éste muere en 1918, víctima de la enfermedad de Hodgkin, Río Hortega le sucederá en la dirección del citado Laboratorio. Don Pío en 1928 va a ser nombrado Jefe de la Sección de Investigación del Instituto Nacional del Cáncer, del que sería director tres años más tarde.

\section{La obra de Río Hortega en Valladolid}

Los más tempranos testimonios documentales que nos han llegado de su actividad científica corresponden al periodo de formación, cuando don Pío estuvo vinculado a la Facultad de Medicina de Valladolid, es su obra primeriza, la menos madura pero no por ello sin interés para el historiador y el biógrafo. La incorporación como alumno de la Academia de Internos de nuestra Facultad, le brindó la amistad perdurable de Ramón López Prieto y su primer interés vocacional por las Ciencias Morfológicas. Las entrañables relaciones mantenidas en las aulas vallisoletanas, proseguirian al correr de los años; figuran entre sus más queridos compañeros, además del ya citado en varias ocasiones Ramón López Prieto, el hijo de don Leopoldo, me refiero a Ángel López Pérez, y otros como Miguel Garcia Canal y Blas Sierra Canal. Las referencias del Archivo Universitario de Valladolid nos dan la pista de las fechas de licenciatura, la de 
López Prieto en 1904, un año más tarde Río-Hortega en 1905, y los restantes alumnos internos en 1906. Dos décadas más tarde, en 1925, todavia permanecía vivo el recuerdo y afecto mutuo de estos compañeros de la Academia de Internos de la Facultad de Medicina, asi se expresa en una carta llena de elogios de Ángel López Pérez, en las columnas de La Clínica castellana. La "Carta abierta a los doctores Ramón López Prieto, Miguel Garcia Canal y Blas Sierra" recogía las siguientes palabras: "La intima amistad que a Pio del Río Hortega me une desde la niñez (...) de los tres grupos que fuimos condiscípulos del ya famoso histólogo del Río Hortega, con el fin de que reuniendo cada uno el mejor número posible de adhesiones de sus condiscipulos y principalmente, de cuantos con él formamos parte del Cuerpo de Internos de la Facultad, se eleve al Directorio que nos gobierna, de Primo de Rivera, una exposición rogando que por excepción, pero no ser de justicia para premiar el mérito sobresaliente del joven histológico español de más positivo valor patrio desde Cajal acá, sea nombrado catedrático de Histología de la Universidad de Madrid (...)n.

La obra de Pío del Río Hortega en la Facultad de Medicina de Valladolid reviste a nuestro juicio enorme interés, constituye el comienzo de su vocación histológica y apunta, aunque de forma todavía balbuciente la orientación por los temas que cristalizarian definitivamente en la siguiente etapa de su vida científica. La labor vallisoletana comprende los primeros años del siglo XX, hasta 1913. Apenas finalizados los estudios de Medicina redactó dos "Memorias" fruto del obligado examen a premio extraordinario de Licenciatura. Los años siguientes, superada la escolarización universitaria, fue más bien parca en realizaciones, es, sin disputa, el periodo más inseguro de la vida científica de nuestro autor, en el que emergiendo su vocación, intentaba Río Hortega encontrar un maestro que le afianzase plenamente. Río Hortega no encontró a buen seguro el clima al que aspiraba en su entorno natal vallisoletano, sus idas y venidas a Madrid que le propiciaron un incidente académico con su maestro López García, evidencian una necesidad imperiosa y vocacional por la Histología. El interés de su estancia en la Facultad de Medicina de Valladolid radica en que Río Hortega se percató de cuál era su vocación, aunque los modestísimos o inexistentes recursos le indicasen que la realización de su aspiración a cultivador genial de la Histología, no podría satisfacerlos en su tierra natal. La opción y su marcha a Madrid era un riesgo, pero a la postre riesgo de afianzar su decidido interés por el cultivo de la Ciencia histológica. A pesar de las manquedades, la genialidad de Río
Hortega sobresale en su meritorio trabajo, tema de tesis de doctorado, Alteraciones del tejido nervioso y sintomas generales en los tumores de encéfalo (Valladolid, 1912). Este trabajo que nosotros recientemente hemos dado a conocer, ha sido prácticamente desconocido por los estudiosos de la obra de Río Hortega, trabajo que evidenciaba la seducción que a la sazón, antes de su marcha a Madrid, habia despertado en nuestro autor la investigación micrográfica. La revista vallisoletana La Clínica Castellana, en los años 191112, publicó este estudio, que más tarde se imprimió en 1912 como un opúsculo independiente.

La tesis doctoral de Río Hortega, dentro de las contadas posibilidades en que hubo de moverse, reviste a nuestro juicio numerosos aspectos novedosos, teniendo en cuenta el clima científico y académico vallisoletano de estos años. Los materiales histopatológicos procedian, como refiere su autor, del antiguo Hospital de la Facultad de Medicina de Valladolid, necropsias que presumiblemente obtuvo de su vinculación a la Cátedra de Anatomía primero y posteriormente de Histología y Anatomia Patológica. Estas palabras de nuestro autor lo confirman plenamente: "Al lado de nuestros queridos maestros, los profesores López García y Simonena, asi como particularmente hemos estudiado varios casos de tumor cerebral procedentes de las clínicas de la Facultad de Medicina y del Manicomio Provincial de Valladolid. Son éstos: dos endoteliomas, un sarcoma, un glioma, un fibroma y un papiloma córneo; un caso de tubérculos múltiples, otro de gran tubérculo reblandecido, dos de tubérculo de cerebelo, un caso de sifiloma, otro de quiste hidatídico y por último un extenso hematoma dural que por sus efectos compresivos obra a manera de tumor. El profesor Suñer nos ha proporcionado amablemente dos interesantes observaciones que le agradecemos y publicamosi. Las Alteraciones del tejido nervioso, se fraguaron en parte con los materiales recogidos en Valladolid y cuya documentación bibliográfica rastreó nuestro histólogo en la misma Facultad, valiéndose de las revistas a la sazón existentes. Años más tarde nos indicará Río Hortega las referencias que incluye al final de su trabajo, pesquisa incompleta por supuesto, pero real debido sin disputa a los exiguos fondos bibliográficos en que hubo de moverse. Con estas palabras lo resume: "Mi buen Maestro don Leopoldo López Garcia -refiere don Pio en su autobiografía- de venerable memoria, hacia a menudo el elogio de Cajal que había conocido en su afición a la eclosión de sus aficiones, a la histología (...). En la modesta biblioteca del laboratorio, formada por algunos libros en francés y en español (la mayoria de éstos,

ARBOR CLXXXI 714 JULIO-AGOSTO (2005) 181-197 ISSN: 0210-1963 
traducciones de otros idiomas), destacaban los "Trabajos del Laboratorio de Investigaciones Biológicas", que publicaba Cajal, cuyos volúmenes ojeaba a menudo don Tomás Gutiérrez Perrín, ayudante como yo de la Cátedra de Histologían. En otras ocasiones hubo de valerse Río Hortega de la inestimable ayuda de la Biblioteca del Ateneo y de los excelentes fondos de que disponía el oftalmólogo vallisoletano Emilio Alvarado. La Biblioteca de Alvarado debió ser la mejor en el Valladolid de la primera década del siglo XX, todavía se conserva a finales de los años cincuenta pero fue desaprovechada la oportunidad de incorporarla a las instituciones locales por razones que ahora no deseamos ahondar. Emilio Alvarado, según palabras textuales de Emilio Hernández Velasco, estudioso de la figura de aquel oftalmólogo, "tenía una biblioteca -concluye el Dr. Hernández- que ya hubiesen querido tener los centro de enseñanza y las diversas entidades científicas".

La elaboración de estos materiales llevaron a recortar a don Pío años más tarde: «Había preparado en tanto, trabajosamente, mi tesis doctoral, documentada como buenamente pude en la biblioteca del Ateneo y, sobre todo, en la del gran oculista vallisoletano Dr. Emilio Alvarado, que me acogió con suma benevolecnia. Era el tema escogido "Anatomía patológica de los tumores cerebrales", y se basaba en unas quince observaciones macro y microscópicas recogidas en mi época estudiantil». Como veremos más adelante, los años hacian el recuerdo impreciso, no eran quince, sino diez observaciones, ni tampoco su tesis doctoral es estrictamente anatomopatológica como señalaré en el curso de mi exposición.

Como años más tarde recordará el gran histólogo castellano, el interés por la investigación se desveló a su paso por la Facultad de Medicina de Valladolid, recuerdo que reflejan de forma puntual sus propias palabras: "Qué admiración sentía -rememorará don Pío- por los discipulos de Cajal en aquella época (Tello, Sala, Villa, Terrazas), colaboradores en los "Trabajos del Laboratorio" y cómo me seducia la aspiración de realizar con el tiempo algo semejante a los de ellos (...). Guiado certeramente por López García, logré iniciarme en las técnicas de colaboración más empleadas entonces, con las que aprendí a deletrear en los tejidos y gocé de no pocas emociones".

La etapa vallisoletana del maestro fue sin embargo el prólogo de su definitiva marcha. Se dijo, su vinculación al claustro vallisoletano se prolongaria hasta finales de 1913.
A lo largo de sus memorias Rio Hortega, en palabras sentidas y con cálida emoción, recordará el incidente de su separación con López Garcia. De forma respetuosa lo recoge nuestro histólogo en estas palabras: "Con Leopoldo, a cuyo carácter pocos se amoldaron, permanecí bastante tiempo sin que tuviera nada que reprocharme. Una vez, es verdad, se enojó seriamente conmigo pero fue porque me ausenté de su ladon. A través de la lejania temporal Río Hortega idealiza una situación que en 1913 debió ser más vidriosa que las anteriores palabras pueden hacernos sospechar. Los documentos del Archivo Universitario de Valladolid, de estas fechas, entre 1913 a 1915 no dejan la menor duda: Rio Hortega hubo de optar por una renuncia forzada a su puesto de auxiliar en la Cátedra de Histología y Anatomía Patológica. Las cartas que hemos consultado ponen de manifiesto, de una parte la personalidad de Pío del Río Hortega, de otra la actitud poco comprensiva de la Facultad de Medicina de Valladolid, especialmente de López García, del Decano Salvino Sierra y del Rector Nicolás de la Fuente Arrimadas, catedrático de Patología quirúrgica. Es además comprensible que al paso del tiempo, visto el incidente de la auxiliaría, quedase reducido a un pormenor del que el gran histólogo minimizaba su importancia, de aquí este generoso juicio para su antiguo maestro: "La inexactitud de estas frases insidiosas me hace sonreír en este momento al recordar el creciente cariño en que trocara, durante mi ausencia, aquel enojo de don Leopoldo López García -a quien aludencuando me separé de su lado y el gozo con que me veía y la emoción con que me llenaba en sus últimos años, de besos y lágrimas». El anciano catedrático vallisoletano, López García, aparece dibujado con profundo afecto en estas breves pero insuperables palabras de su más alto discípulo.

Cuando superados los años de fecunda labor investigadora, recoja en sus "memorias» Río Hortega los recuerdos lejanos y enjuicie su tesis del doctorado, también el tiempo borrará fronteras y su juicio idealizaria una realidad, que en alguna medida fue diferente a como la veía en plena madurez nuestro histólogo. Para Río Hortega su tesis del doctorado correspondia a un trabajo, refiere textualmente sobre "Anatomia patológica de los tumores cerebrales", calificativo que debe ser matizado. Las Alteraciones del Tejido nervioso y síntomas generales de los Tumores de Encéfalo, no es un estudio de anatomía patológica pura, al contrario, es un conjunto de diez casos cínicos con aportaciones anatomopatológicas. Es un estudio anatomoclínico con aportaciones a la clinica de los sindromes de hipertensión craneal ocasionada por procesos "tumorales», entre los que Río Hortega incluye, entre 
diez casos recogidos, un quiste hidatídico y un sifiloma. El opúsculo de Río Hortega, impreso en 1911-12, se mueve todavía más en la orientación anatomoclínica charcotiana del siglo XIX, que en la corriente histopatológica pura de la escuela cajaliana. Corresponde a la tarea clínica de las salas de los profesores Antonio Simonena, catedrático de Patología médica, y Enrique Súñer de Pediatría. Esta orientación "todavian clínica se corrobora por la amplitud que Rio Hortega consagra al sindrome de compresión cerebral, y especialmente a los trastornos del sueño que le acompañan, capitulo del que nos hace una pormenorizada exposición doctrinal. En cambio, son más modestas sus aportaciones técnicas, elementales en la investigación histopatológica, por lo que su tesis del doctorado, a nuestro juicio, se orienta todavía en un nivel anatomoclínico, que cualitativamente será superado en la siguiente etapa de su vida de investigador. Cuando se instale en Madrid, la clara especialización en la histopatología pura se produjo de forma súbita al vincularse al Laboratorio madrileño y a la Junta para Ampliación de Estudios. Este criterio que sustentamos olvidado por nuestro histólogo en sus "memorias", se halla presente en el texto de su tesis del doctorado, texto que los años habian hecho olvidar a Río Hortega: «El método anatomoclínico aplicado a la Psiquiatria, ha permitido descubrir la relación de causalidad entre los trastornos psíquicos y las relaciones de la corteza cerebral, y de los trabajos más recientes se saca la conclusión de que el trastorno funcional depende de la localización y extensión de las lesiones, más que de su naturaleza e intensidad". No cabe la menor duda; Río Hortega, doctrinalmente, se alinea con la neuropatología clásica localizacionista del siglo XIX.

Semejantes conclusiones deben desprenderse del estudio particularizado de las técnicas y métodos histológicos empleados por Río Hortega en la elaboración del opúsculo Alteraciones del tejido nervioso. Sus conocimientos técnicos se limitan tan sólo, en 1911, a la tionina de Nissl y al método de Weigert-Pal, más aún confiesa Río Hortega, en su trabajo, que uintentamos sin éxito la colaboración de las neurofibrillas por el método de Cajal». A pesar de estas indudables vacilaciones y limitaciones metodológicas, los diez casos clínicos objeto de estudio, nos orientan sobre las preferencias del futuro gran histólogo, es decir la neurohistopatología, a la que dedicaría toda su vida.

La fugaz y efímera vinculación docente de Rio Hortega como auxiliar de la cátedra de Histologia y Anatomía patológica revela las dificultades que su permanencia en este claustro le hubieran ocasionado. A pesar de las ausencias, en sus viajes a Madrid, el incidente provocado por Leopoldo López García nos da la pista del juicio negativo que, al menos en estos años, tuvo de nuestro científico. A lo largo de 1913, reiteradamente, Lepoldo López García insistió en el cese de Río Hortega, alegando ausencias injustificadas. El 17 de junio de 1913 informaba al Decano de la Facultad, Salvino Sierra, que: "la conducta académica que ha seguido durante el curso actual el Sr. Auxiliar interino de mis dos Cátedras, don Pío del Río, no se ha ajustado, ni a las reglas de la buena disciplina académica, ni a las costumbres de la cortesía, que debe ser la caracteristica de todo personal subalternon. En los últimos días del mes de noviembre de 1912, a consecuencia de un catarro laríngeo, se encontraba Lepoldo López García de baja académica, encargándose durante ocho dias de la enseñanza Río Hortega. La salida precipitada de éste a Madrid obligó al titular de la Cátedra, sin estar plenamente restablecido, a reanudar su actividad docente. Dos nuevas salidas a Madrid de Río Hortega fueron la causa de la ruptura y su abandono del claustro vallisoletano. La razón nos la daría Río Hortega en su obra Mi maestro y yo, cuando sugiere que "sustituyendo, en diversas ocasiones, a mi maestro en la docencia, pude convencerme de que por ese camino no podía llegar lejosn. Su primera experiencia docente debió ser poco grata, pues confiesa upadecía frecuentes inhibiciones que me ponian en trances difíciles». El resultado para Río Hortega fue su marcha definitiva del claustro vallisoletano. ¿Es sincero Río Hortega cuando años más tarde recordaba el incidente con López García? Aunque no podamos dar una respuesta definitiva, es necesario subrayar que cuando el histólogo castellano nos relata en plena madurez, no concuerda con la documentación de los años 1913-14. "Tuve aversión a la Cátedra, que era para mi temperamento apocado un pequeño suplicio. El laboratorio me encantaba, pero era odioso que tuviere que arrastrar el lastre de la enseñanza teórican. Quizás las ausencias de las que López Garcia hizo motivo de censura, estaban relacionadas con el propósito de Río Hortega de incorporarse como Jefe de Sección del Instituto del Cáncer. Como nuestro autor relata, solicitó inmediatamente la admisión al concurso y acabado el plazo de instancias «marché a Madrid dispuesto a toda clase de esfuerzos para conseguir mi propósiton, confesaba Río Hortega. El incidente se prolongaría durante los años siguientes, de nuevo en enero de 1915, Río Hortega reclamaba al rector de la Universidad de Valladolid cantidades correspondientes a los derechos de examen. Habiendo desempeñado la plaza de auxiliar pretendió participar en las remuneraciones de los años 1911, 1912 y 1913, de las

ARBOR CLXXXI 714 JULIO-AGOSTO (2005) 181-197 ISSN: 0210-1963 
que Salvino Sierra, Decano de la Facultad de Valladolid, le había excluido. Como cabía esperar la resolución del Rector, Nicolás de la Fuente Arrimadas, catedrático de Patología quirúrgica de la Facultad de Medicina, ratificó la anterior decisión de excluir por ausencia al auxiliar de la cátedra de Histología y Anatomía patológica. A partir de su renuncia a la auxiliaría el 31 de diciembre de 1913, quedaba cerrada definitivamente la primera etapa de su vida científica.

\section{BIBLIOGRAFÍA CONSULTADA}

Aguado Aguado, Primitivo: Historia de la Facultad de Medicina de Valladolid. Tesis doctoral. Universidad de Valladolid, 1981.

Aguirre Viani, César: La obra histológica de Pio del Río Hortega. Valladolid, 1978.

Aguirre Viani, César: Cajal y su Escuela. Valladolid, 2002.

Buño, W.: «Don Pío del Río-Hortega: bosquejo parcial de su obran, Revista Neuropsiquiátrica, VIII (1945), 263-387.

Cano Díaz, Pedro: Una contribución a la Ciencia histológica: la obra de Don Pío del Río-Hortega. Madrid, 1985.

Fernández-Santos Gutiérrez, Rafael: Los Libros de Actas 1907-1939 de la Facultad de Medicina. Tesis doctoral. Universidad de Valladolid, 1986.

Fernández Rodriguez, Carlos: La Clínica Castellana 1910-1930. Tesis doctoral. Valladolid, 1986.

Garcia González, Raquel: Licenciado en Medicina y Cirugía en la Universidad de Valladolid (1871-1936). Valladolid, 1979.

Granjel, Luis S.: La Medicina española contemporánea. Salamanca, 1986.

López de Letona, Carlos: Don Isidro de la Villa y la Medicina contemporánea. Valladolid, Universidad, 1990.

López Prieto, Ramón: «La juventud de Río-Hortegan, Anales de la Real Academia de Medicina de Valladolid, IX (1971), 75-79.

Ortiz Picón, Juan Manuel: «La obra neurohistológica del Doctor Pío del Rio-Hortegan, Archivos de Neurobiología, XXXIV (1971), 39-70.

Polak, Moisés: "Pío del Rio-Hortega 1882-1945", Archivos de Histología normal y patológica, III (1947), 377-421.

Riera Palmero, Juan: La obra de Pío del Rio-Hortega en Valladolid. Valladolid, 1991.
Riera Palmero, Juan: Los estudios de Medicina y los médicos en Valladolid (1404-2004). Valladolid, 2004.

Rio-Hortega, Pío del: Epistolario y otros Documentos. Primera Parte (1902-1930). Valladolid, Universidad, 1993; 504 págs. llustr. 


\section{PÍO DEL RÍO-HORTEGA*}

Tercicios de Licenciatura

Archivo Universidad de Valladolid

Expediente de Licenciado legajo 621-80

Grado de Licenciado en 16 de Junio de 1905. Libro 2085, fol. 57

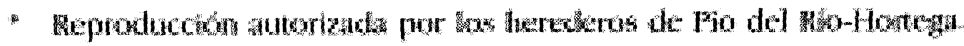

ARBOR CLXXXI 714 JULIO-AGOSTO (2005) 181-197 ISSN: 0210-1963 


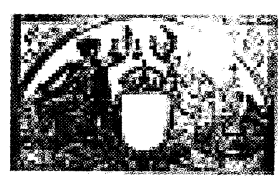

A.5.55220*

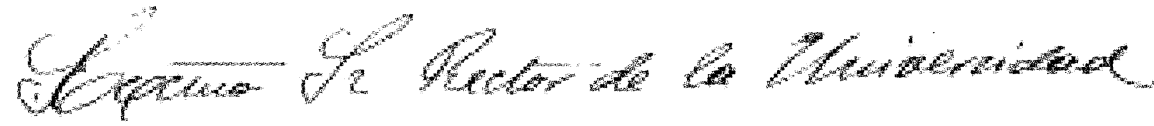

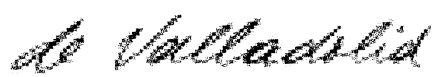

26.40: 18

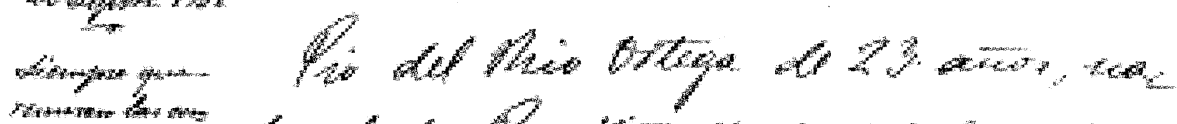

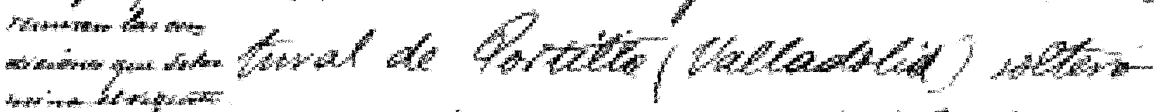

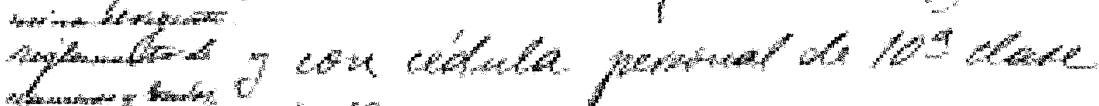

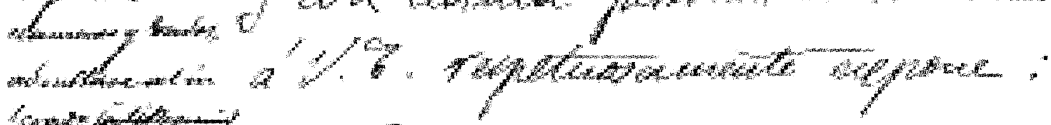

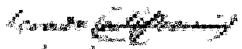

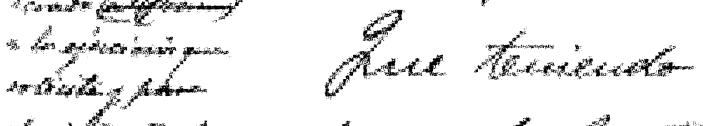

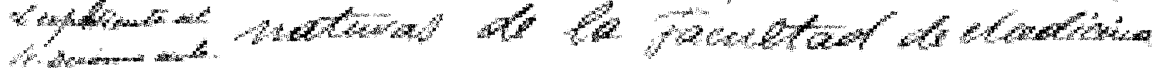

tom

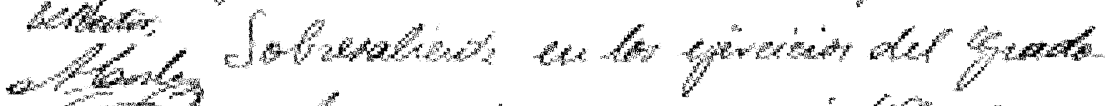

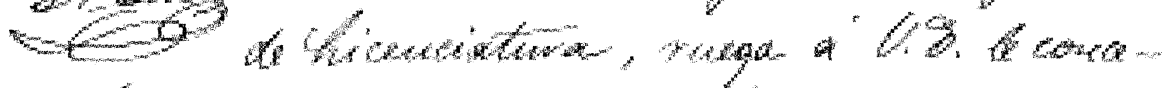

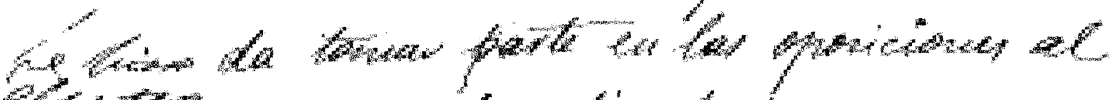

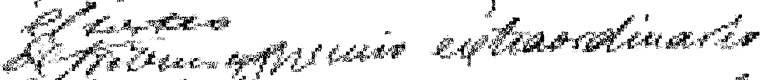

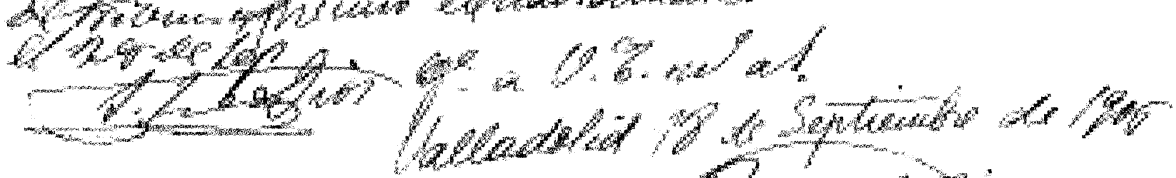

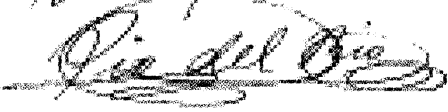



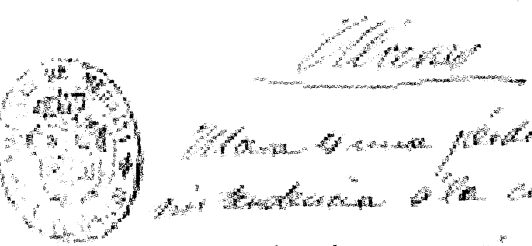

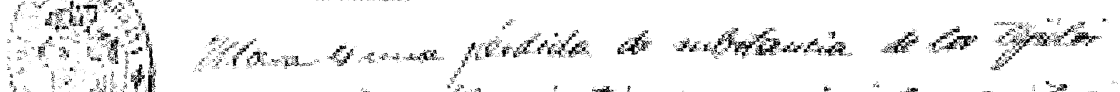

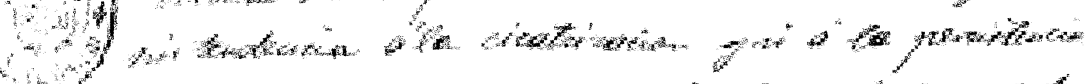

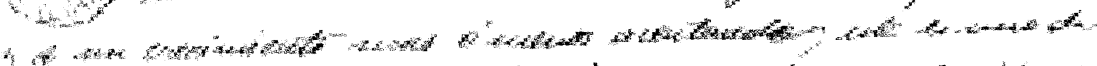

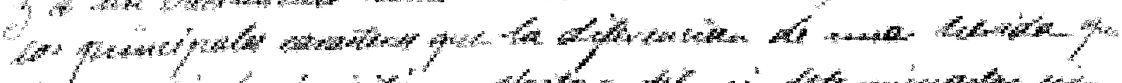

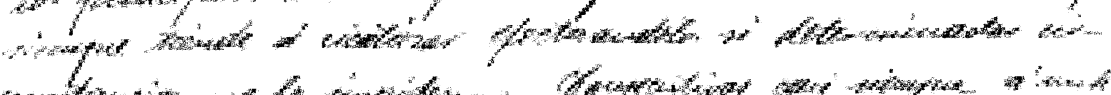

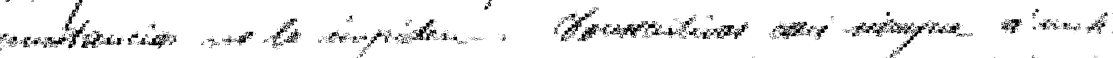

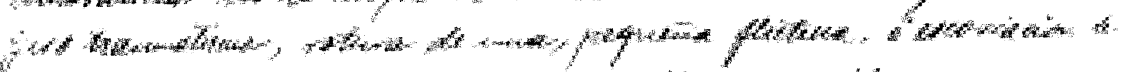

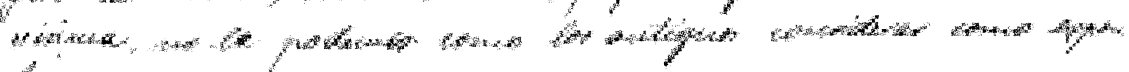

Howe

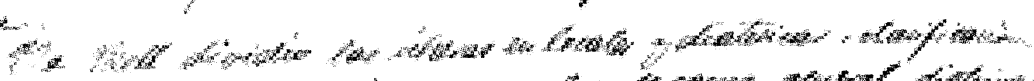

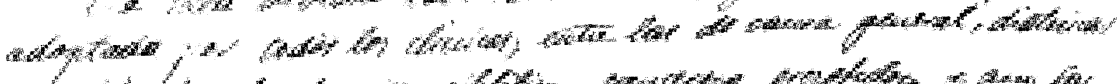

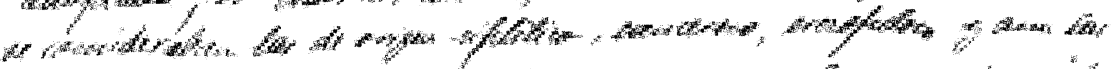

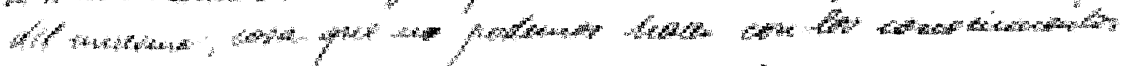

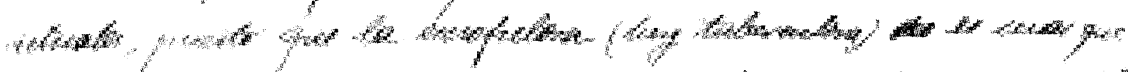

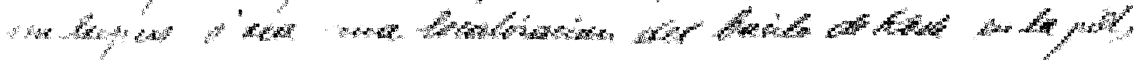

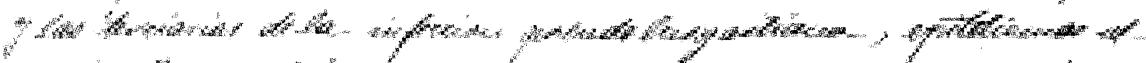

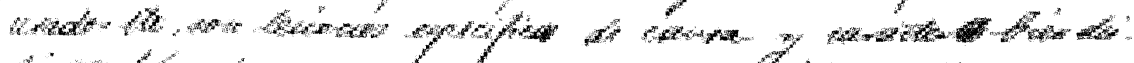

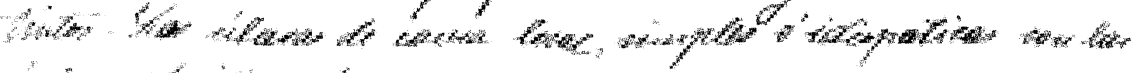

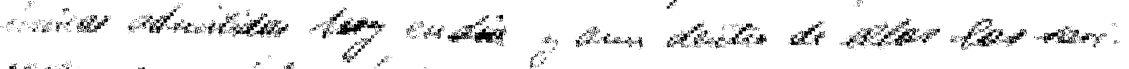

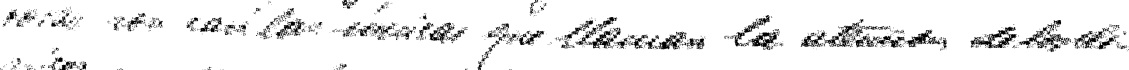

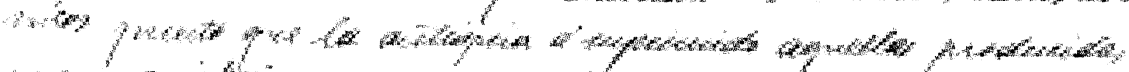

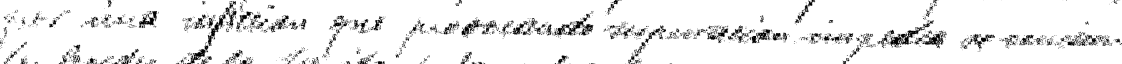

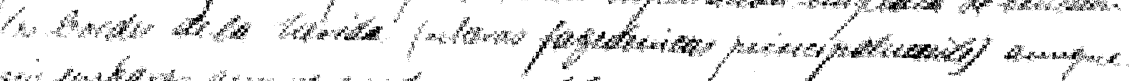

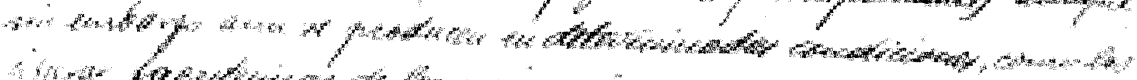

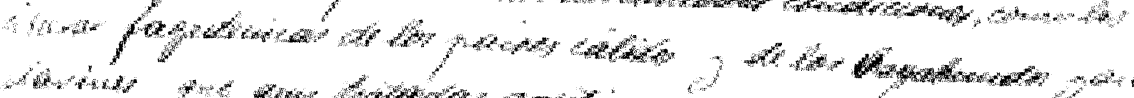

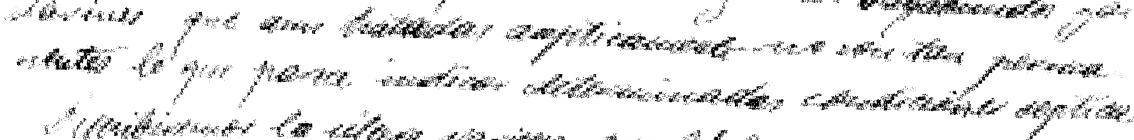

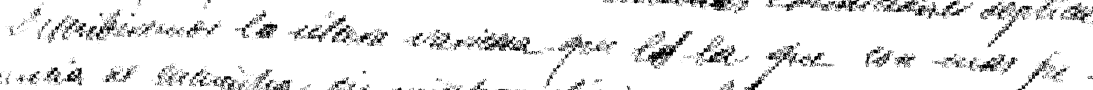

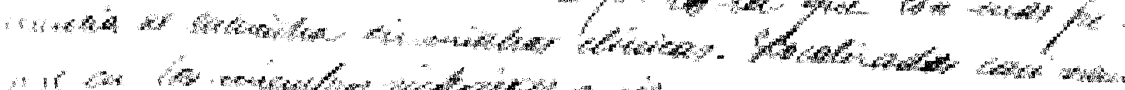

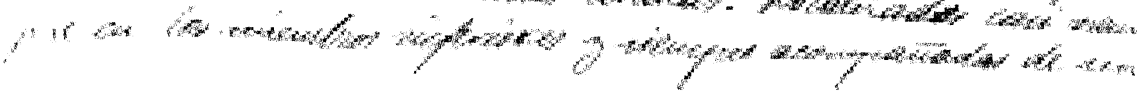

ARBOR CLXXXI 714 JULIO-AGOSTO (2005) 181-197 ISSN: 0210-1963 


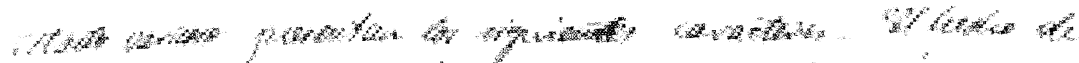

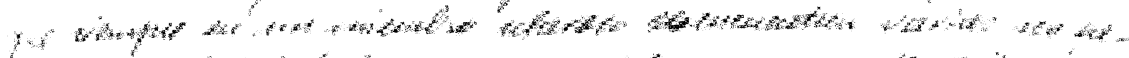

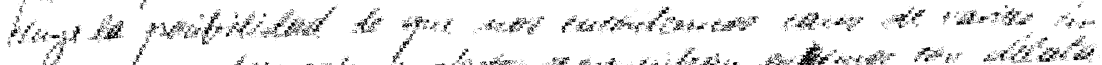

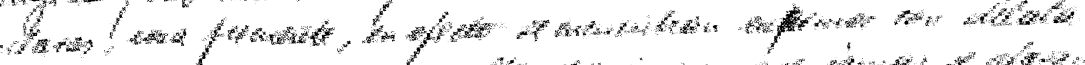

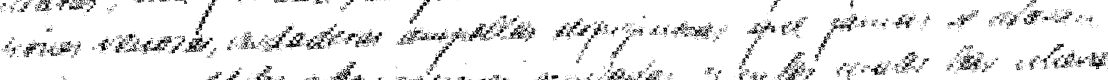

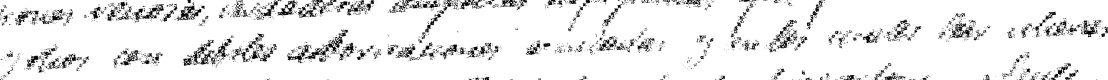

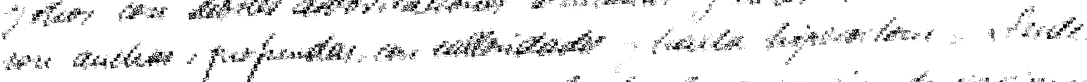

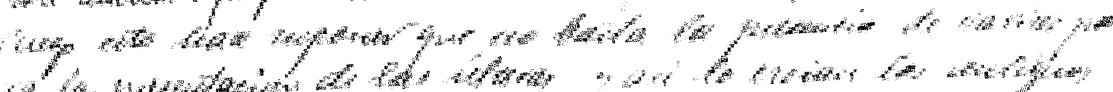

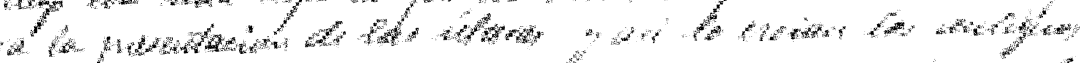

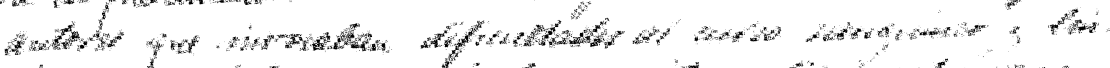

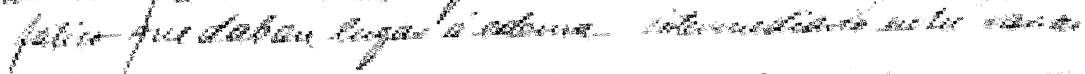

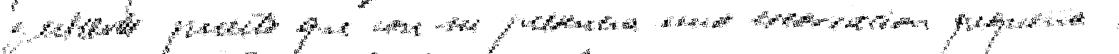

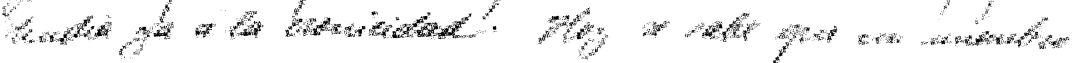

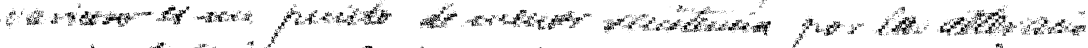

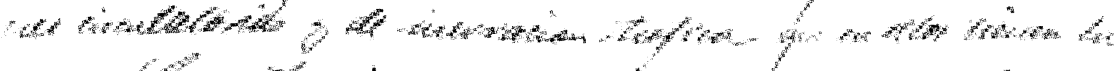

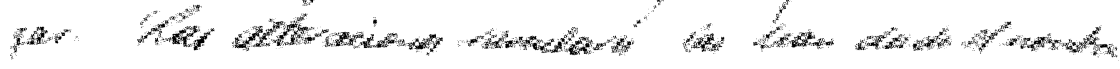

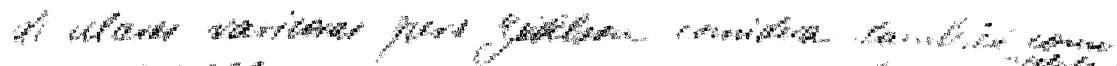

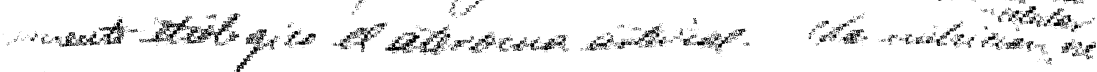

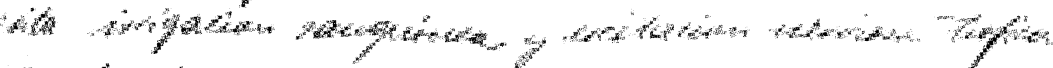

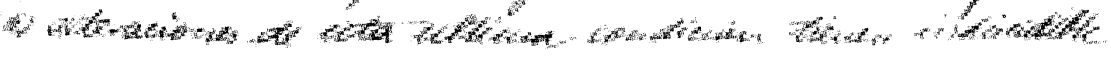

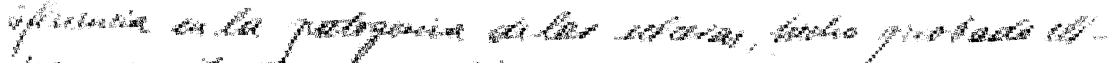

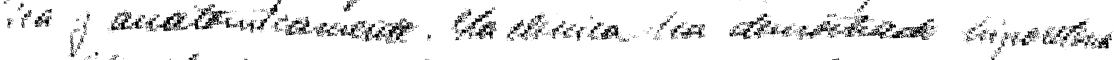

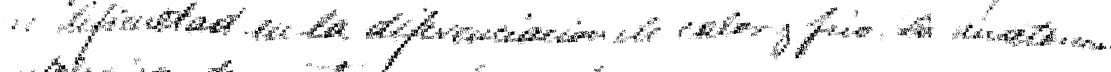

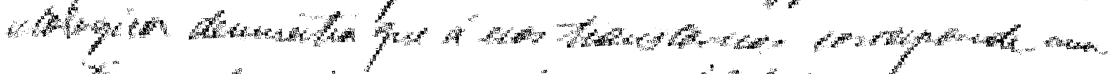

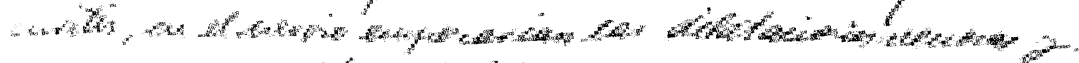

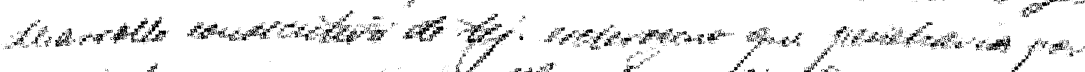

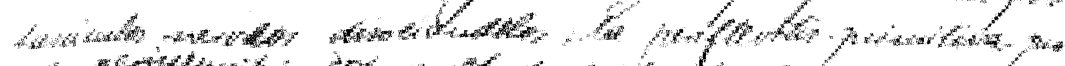

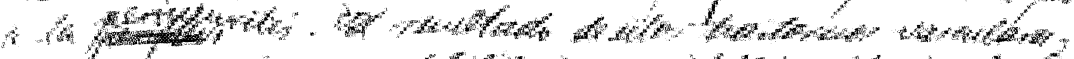

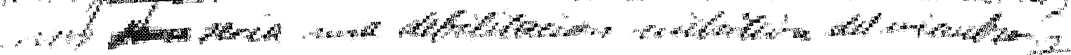

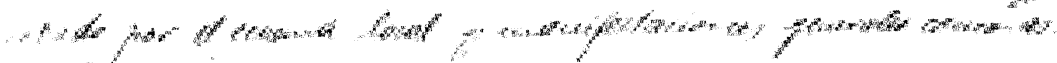

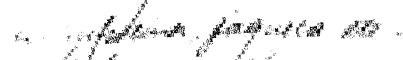

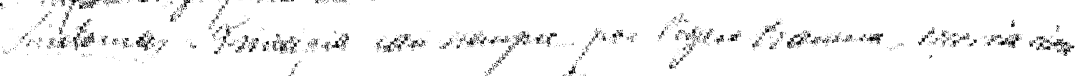

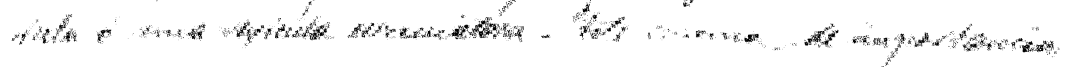

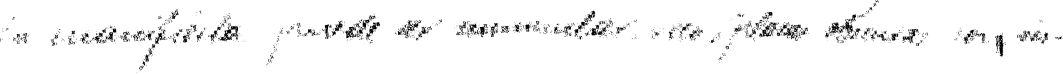




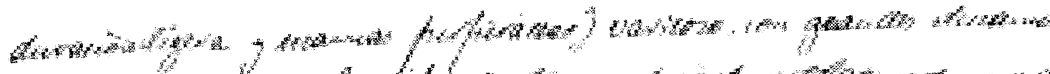

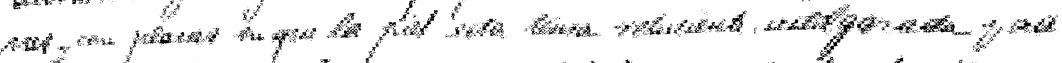

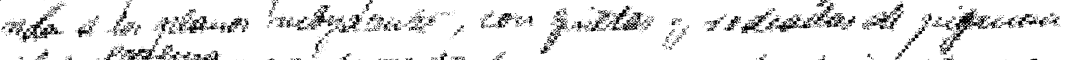

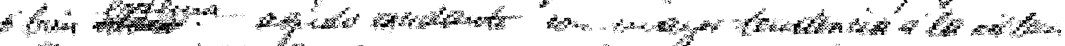

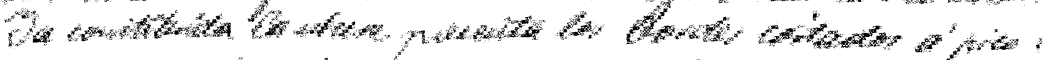

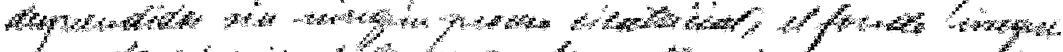

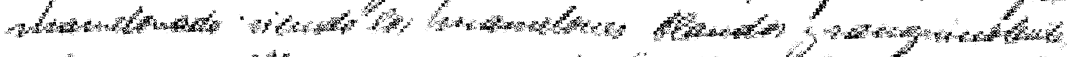

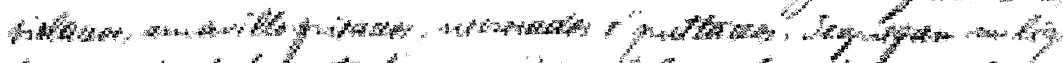

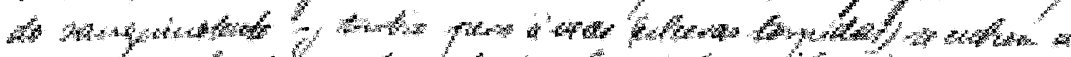

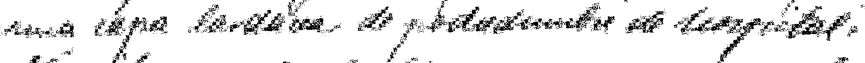

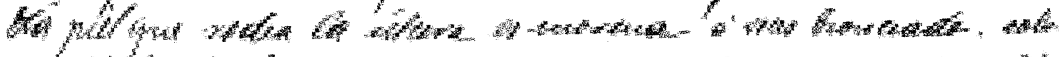

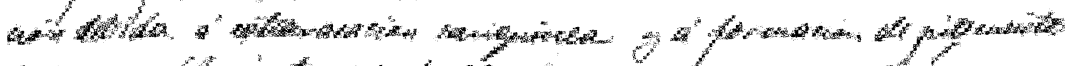

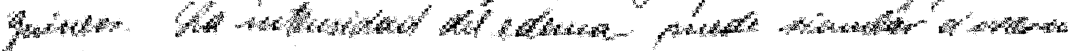

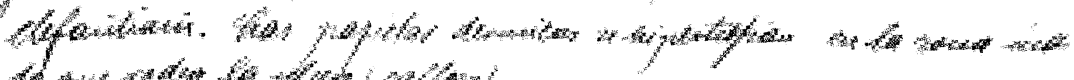

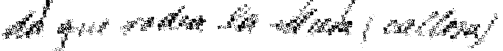

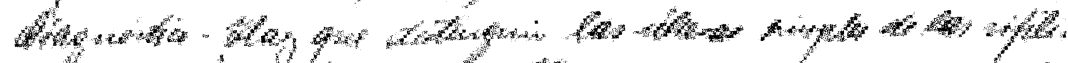

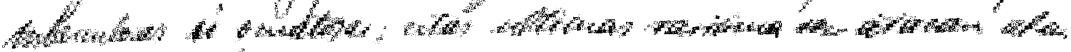

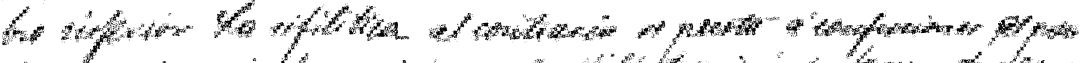

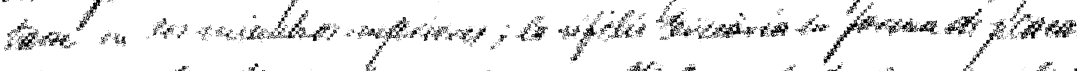

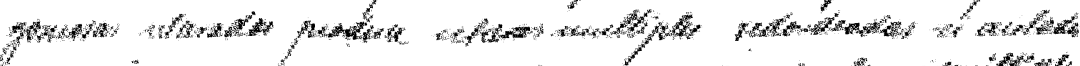

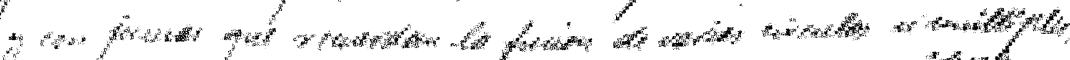

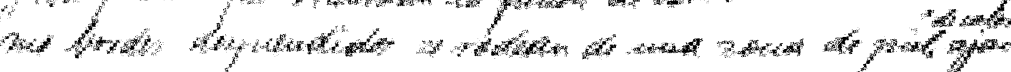

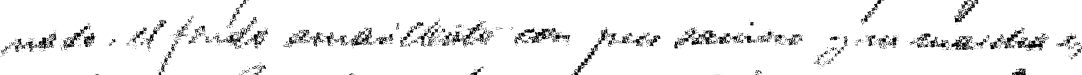

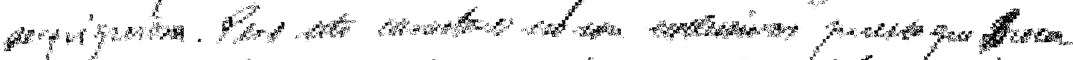

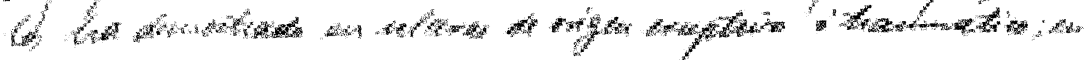

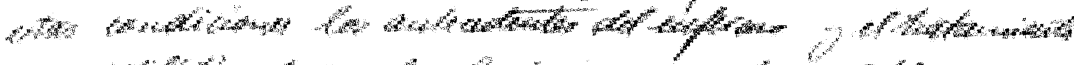

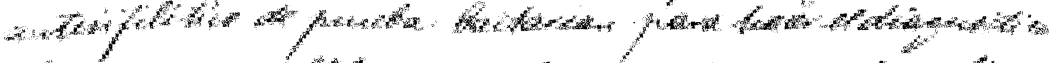

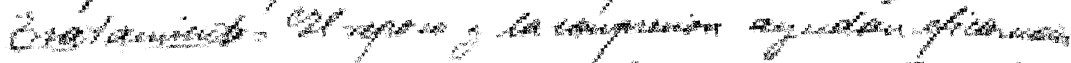

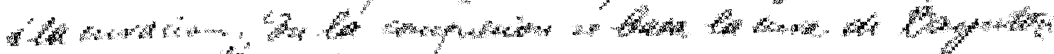

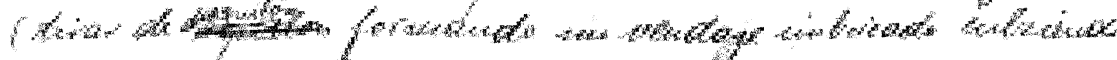

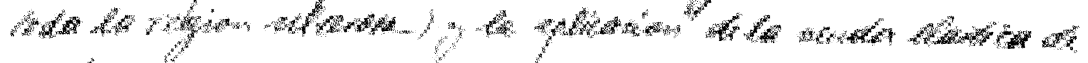
iandes?

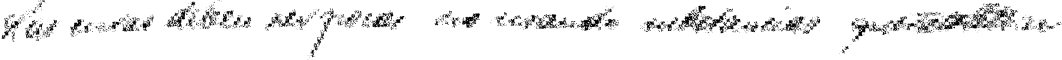

ARBOR CLXXXI 714 JULIO-AGOSTO (2005) 181-197 ISSN: 0210-1963 


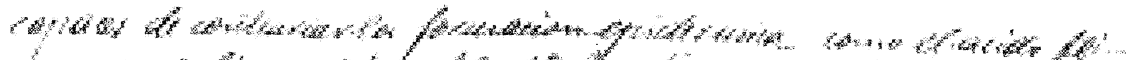

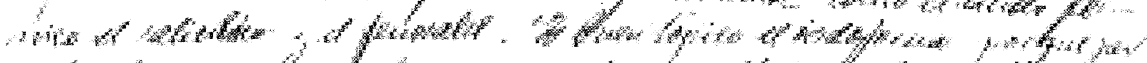

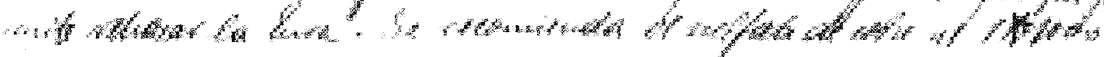

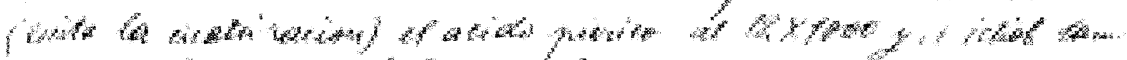

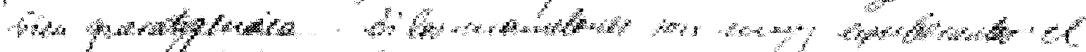

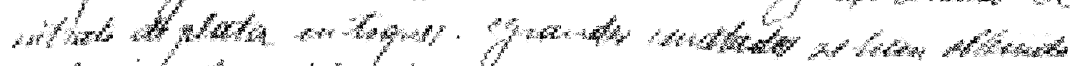

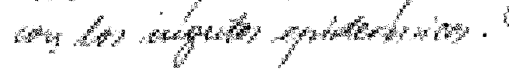

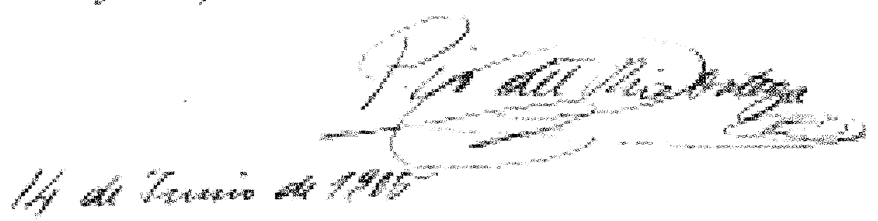




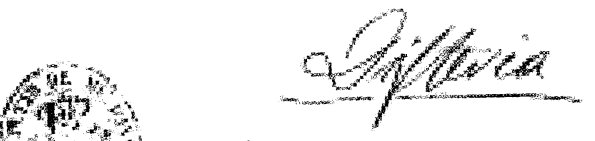

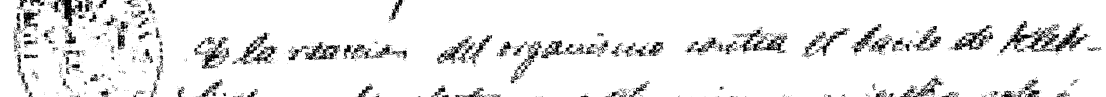

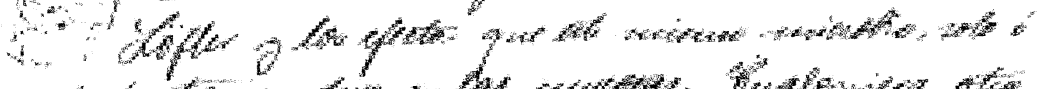

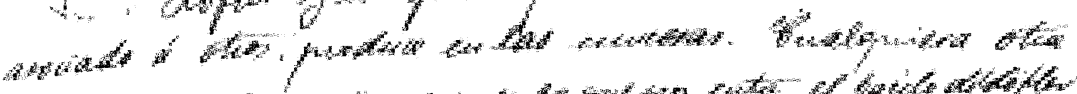

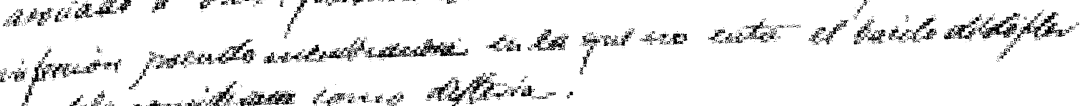

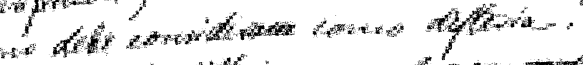

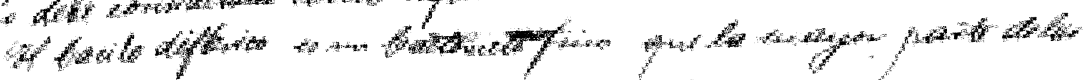
rot of

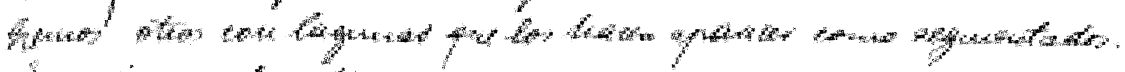

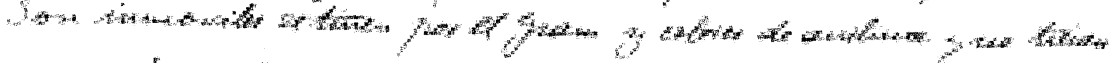

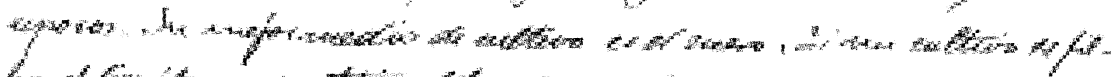

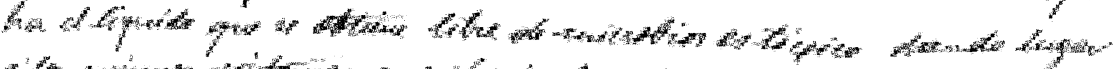

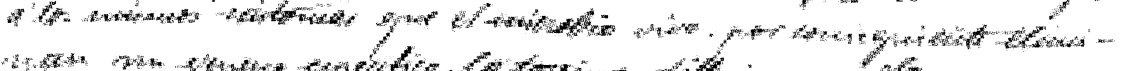

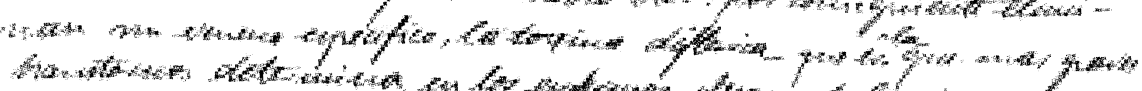

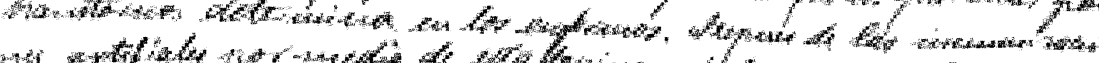

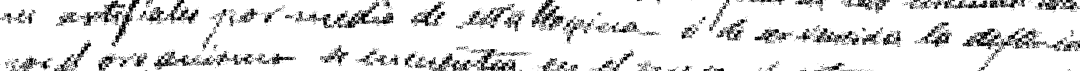

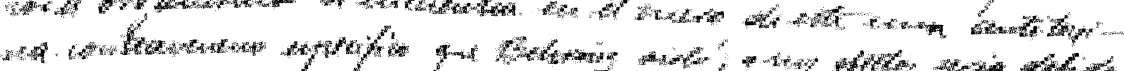

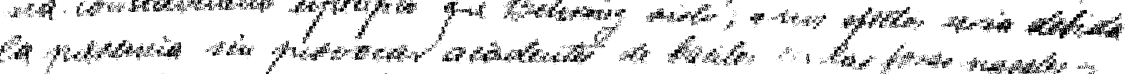

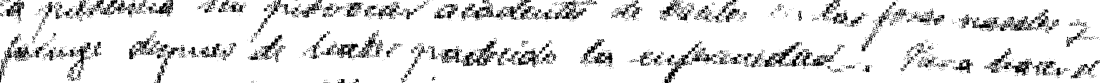

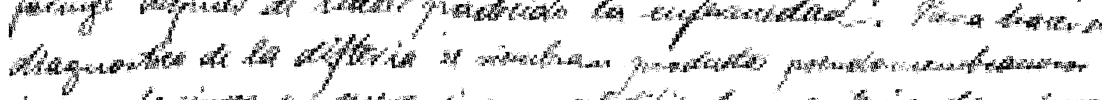

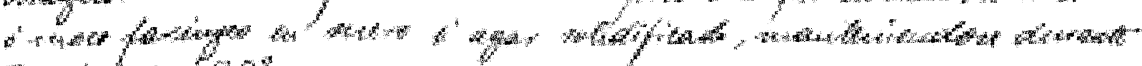

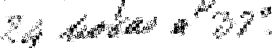

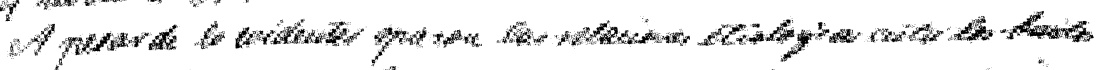

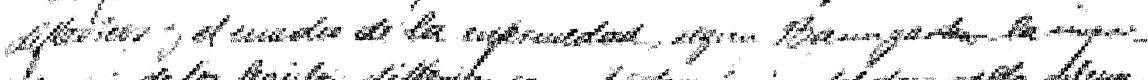

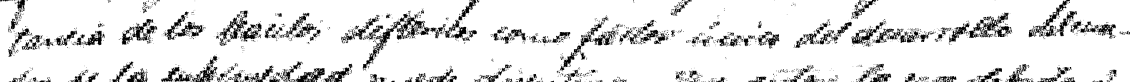

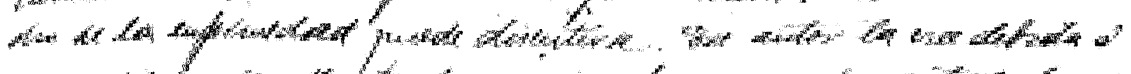

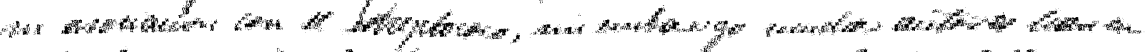

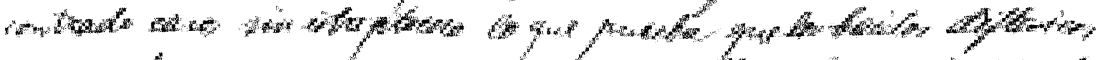

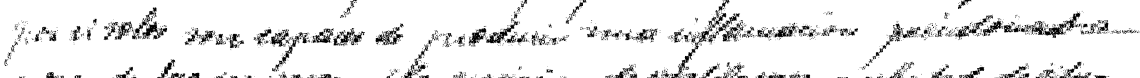

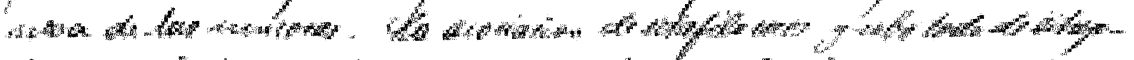

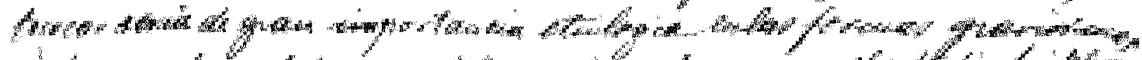

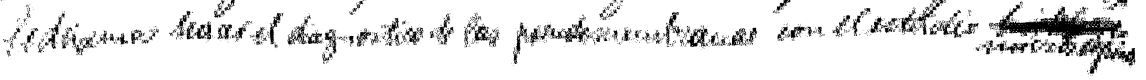




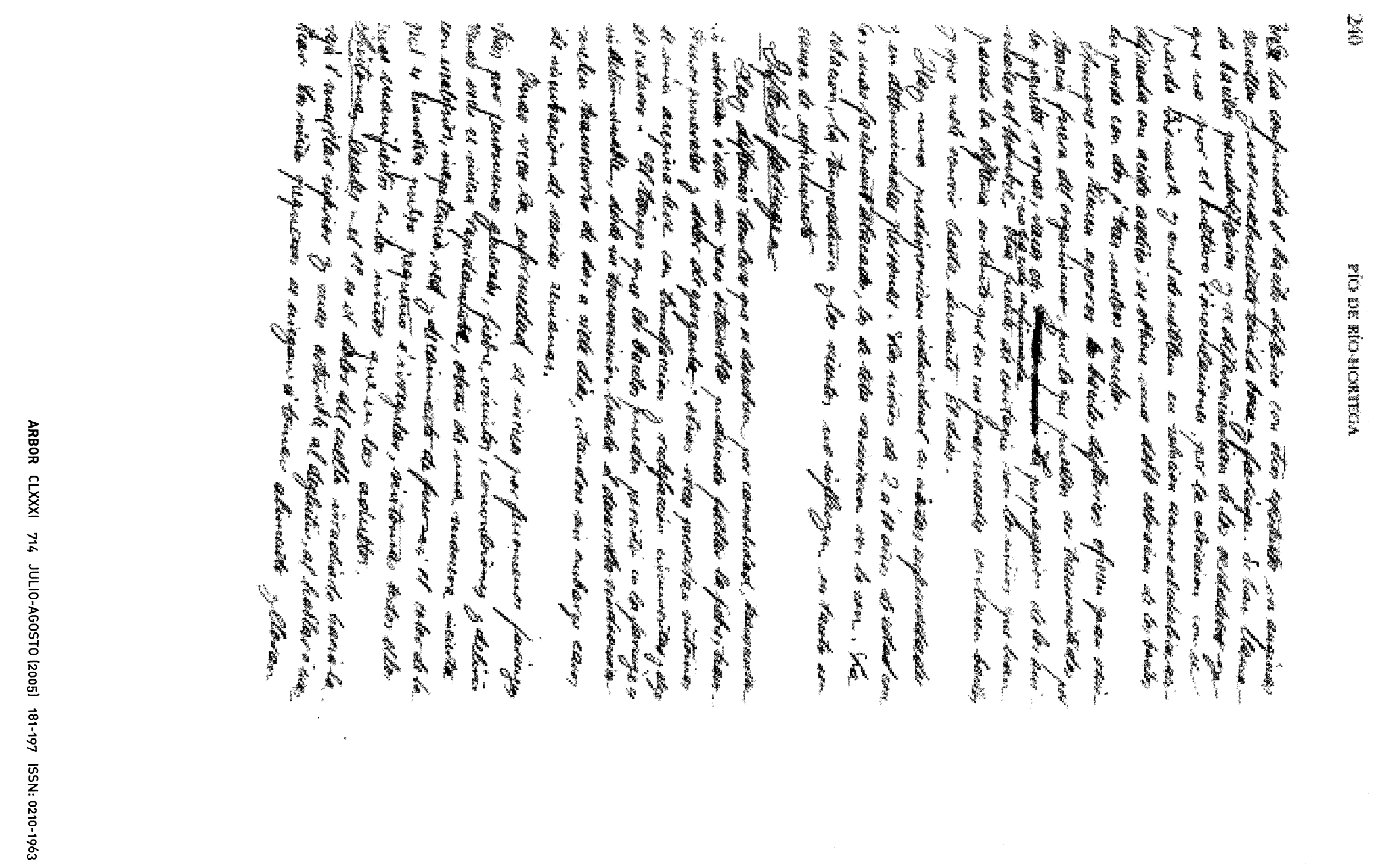




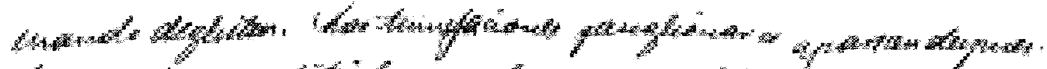

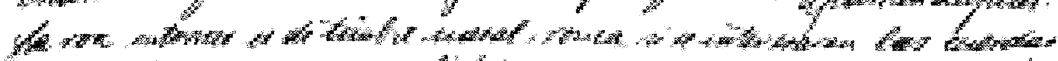

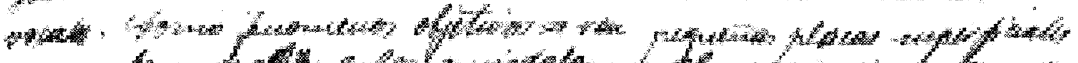

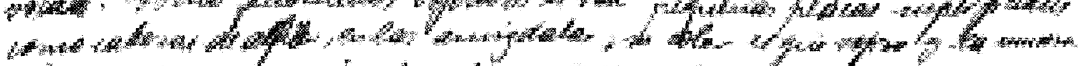

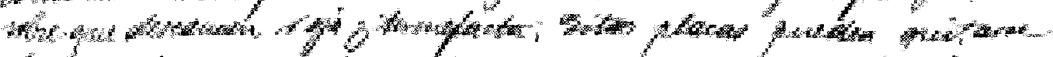

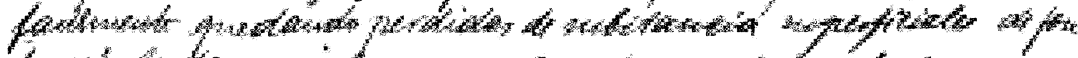

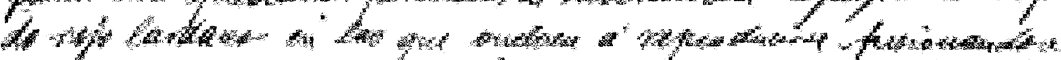

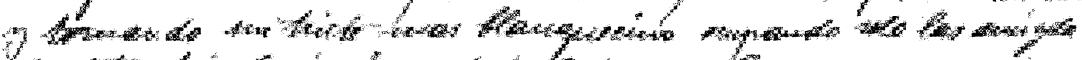

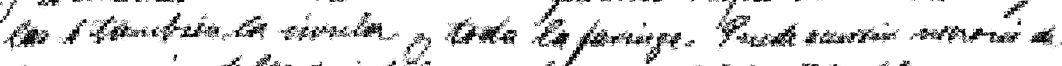

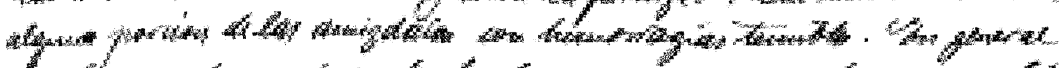

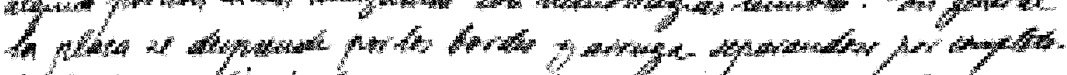

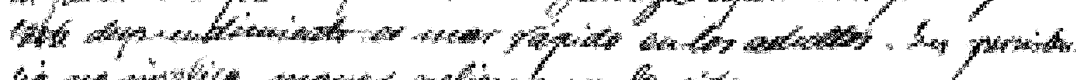

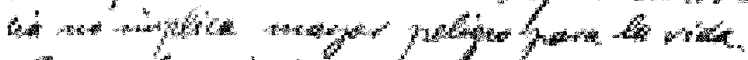

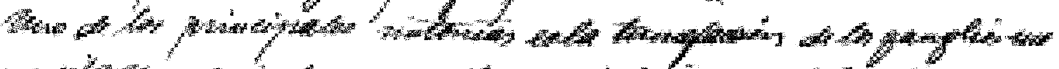

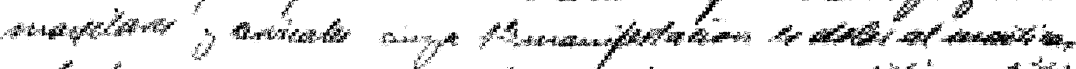

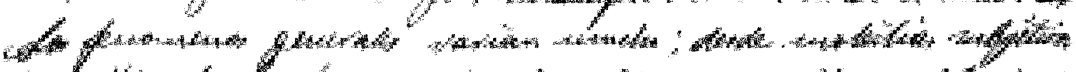

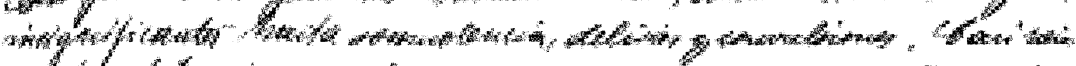

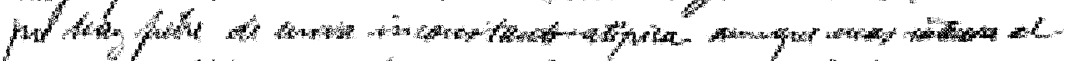

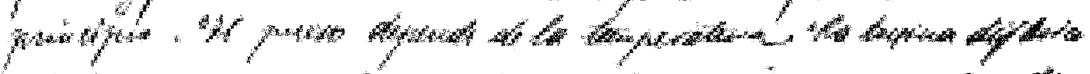

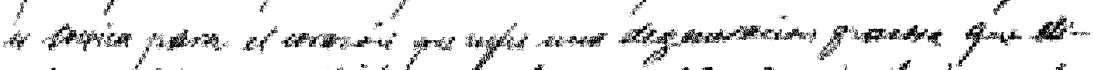

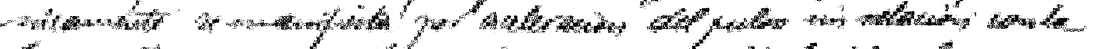

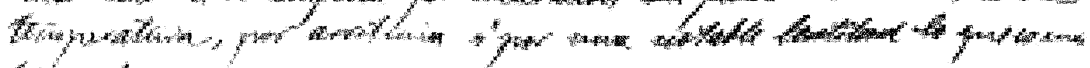
frawert.

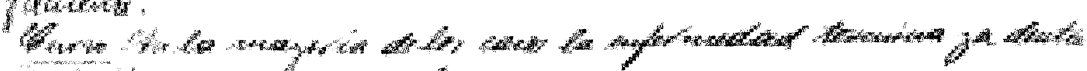

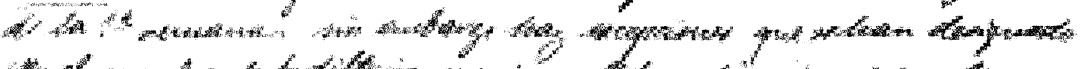

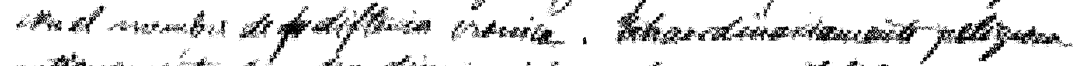

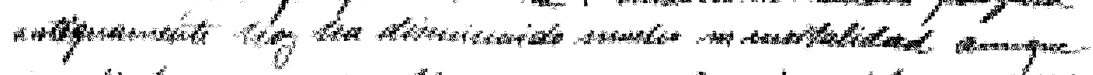

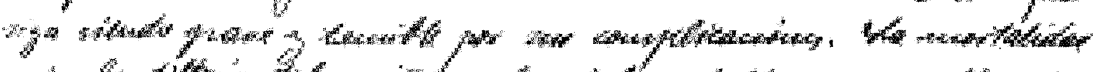

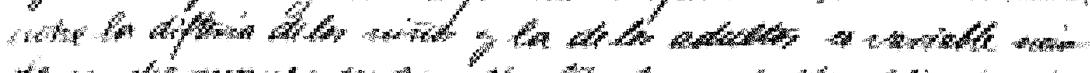

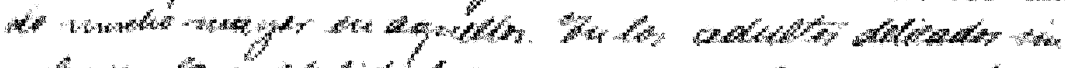

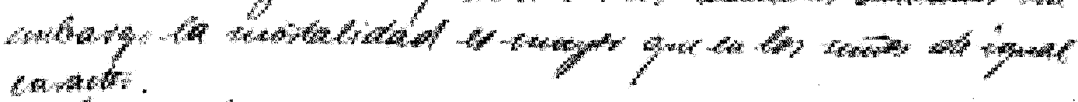

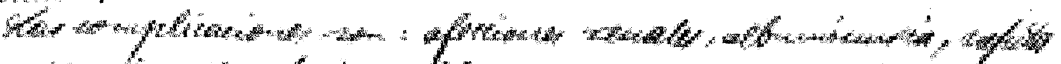

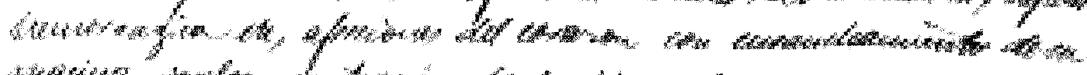

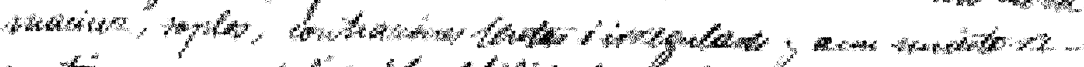

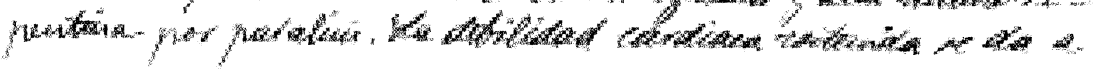




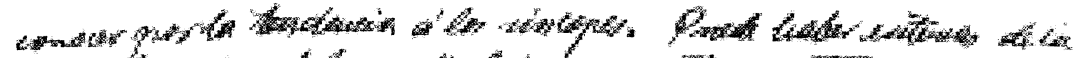

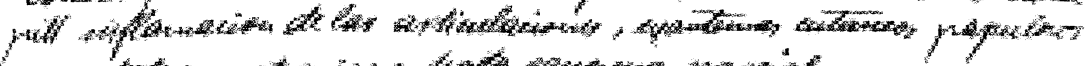

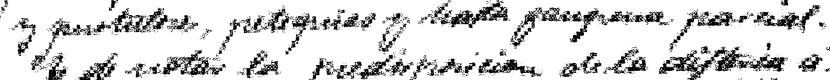

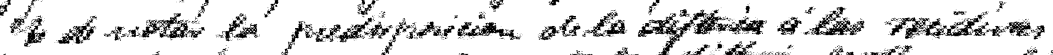

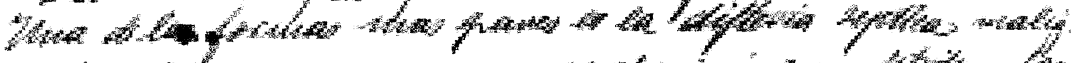

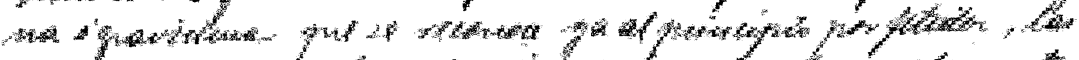

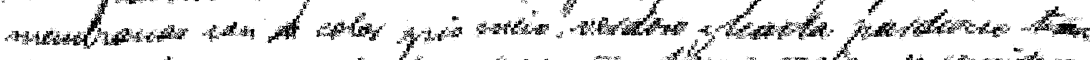

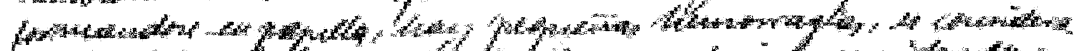

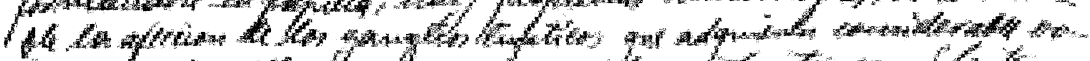

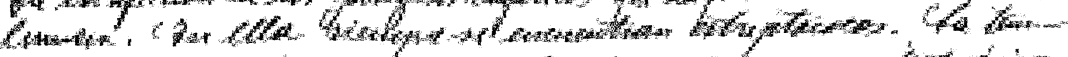

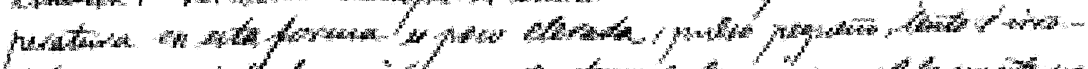

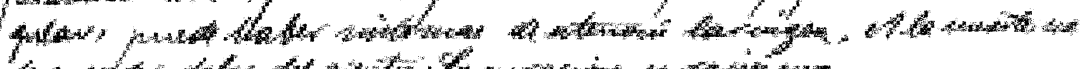

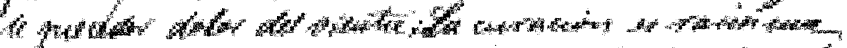

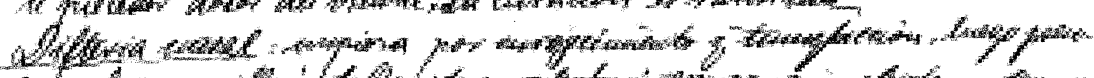

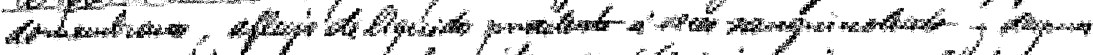

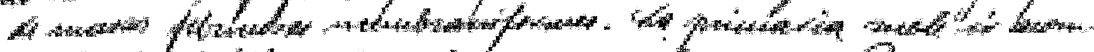

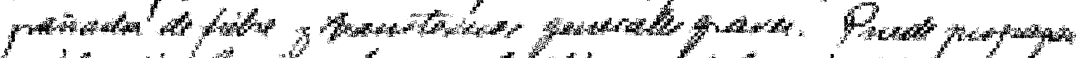

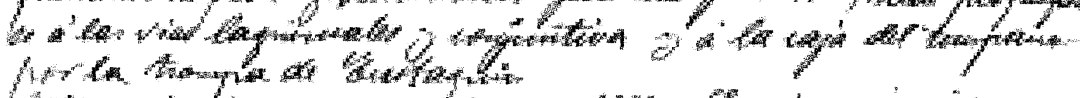

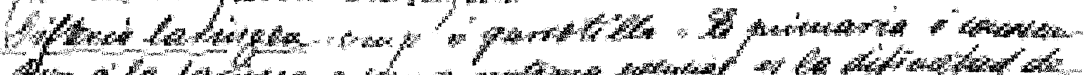

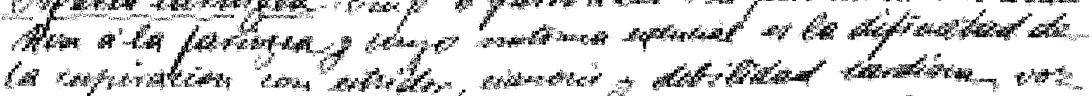

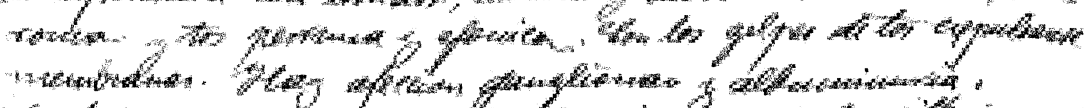

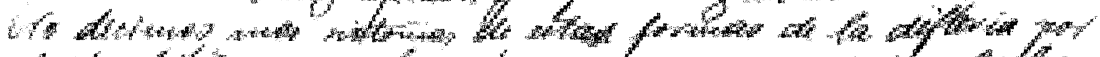

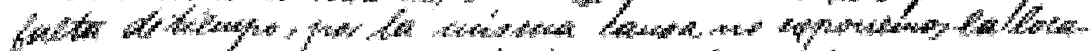

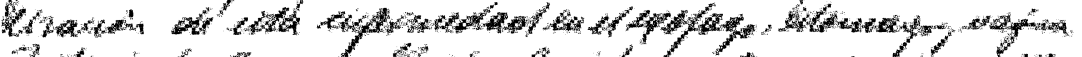

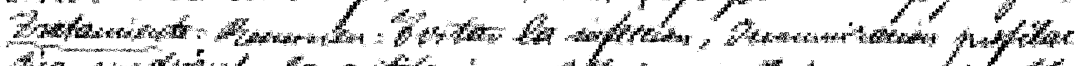

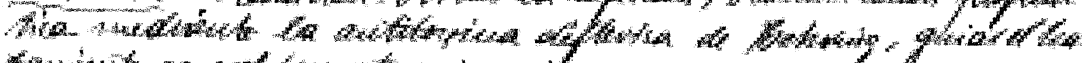

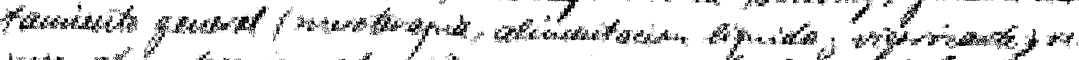

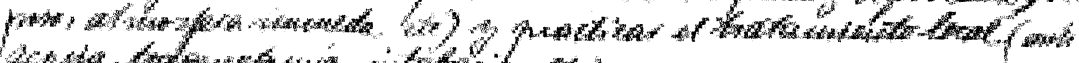

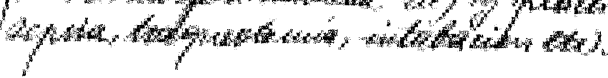

14 when ar tops

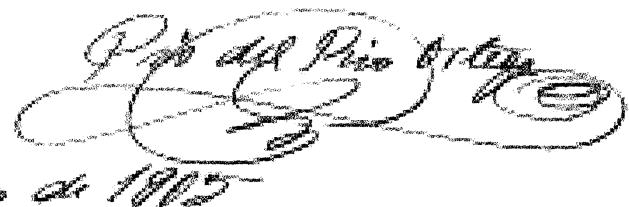

